\title{
COOPERAÇÃO, O QUE VEM A SER?
}

Ludmila Moreira Lima*

Resumo: Dentro da tradição sociológica, afirma-se que a cooperação estabelecida entre indivíduos, grupos e categorias sociais constitui uma das formas de ação coletiva que mais despertaram interesse de estudo, na medida em que a própria sociedade é entendida como "uma extensa rede de colaboração entre os mais diversos atores sociais". O presente artigo tem por objetivo fazer uma incursão na tradição do pensamento sociológico e antropológico de modo a sinalizar referenciais teóricos que possibilitem entender melhor as representações que hoje se agregam à prática da cooperação para o desenvolvimento.

Palavras-chave: cooperação, conflito, poder

\begin{abstract}
Within the sociological tradition, the cooperation among individuals, groups and social categories as a collective action is one of the most matters of reaserch, due the fact that society itself is understood as a broad network of cooperation among social actors. This article aims at undergoing an incursion in the tradition of the social and antropological thought in order to point out a number of theoritical matters for better understanding the representation that have been incorporated to the cooperation for the development.
\end{abstract}

"Escrever sobre cooperação e solidariedade significa escrever, ao mesmo tempo, sobre rejeição e desconfiança... Algumas vezes a confiança tem breve duração e é frágil, dissolvendo-se facilmente e resultando em pânico. Algumas vezes a suspeita é tão profunda que a cooperação torna-se impossível”. (Mary Douglas, 1986)

Para os que hoje se aventuram em compreender um conjunto diverso de práticas, experiências e relações oficialmente acordadas e/ou genericamente definidas em certos contextos e campos discursivos como "cooperação" o desafio é grande.

Primeiramente, deve-se considerar que o conceito não possui um sentido unívoco. No discurso social elaborado por agentes governamentais e não-governamentais, verificam-

\footnotetext{
* Mestre em Sociologia pela Universidade Federal do Rio de Janeiro (UFRJ) e Doutora em Antropologia Social pela Universidade de Brasília (UnB). Prestou consultorias como antropóloga a Projetos Governamentais, envolvendo parcerias com ONG's e organismos de cooperação internacional e hoje é professora de Sociologia, Antropologia e Cooperação Internacional no Curso de Relações Internacionais do Centro Universitário Euro-Americano (UNIEURO) em Brasília/DF. Coordena, também, nesta Instituição, a linha de pesquisa "Cooperação Internacional: discursos e representações". E-mail: ludmila@euroamericana.com.br
} 
se convergências de significados conforme a articulação do termo a noções de sentido julgado correlato ou intrínseco, por definirem relações decisivas, instauradoras ou decorrentes da cooperação, como "interdependência", “integração", "solidariedade" e "desenvolvimento".

No campo das ciências sociais, os processos cooperativos são vistos como instauradores de solidariedades, lealdades, ordem e equilíbrio social, ou ainda como arena de conflitos e dominação e, por essas razões, têm sido considerados prioridades de estudo para a sociologia e a antropologia. Todavia, não se instaurou, a partir daí, um campo de reflexão que, elegendo a cooperação como foco, esteja hoje sujeito a balanços críticos e revisões teóricas. Ou seja, apesar da importância atribuída a essa prática social - e ao amplo e diversificado leque de temáticas que ela propicia - as ciências sociais não se mobilizaram para fundar um campo de estudos ${ }^{1}$ que nos permita avaliar o percurso dessa problemática de contornos interdisciplinares no contexto de suas fecundas produções. ${ }^{2}$

Se a ausência de uma literatura específica dedicada às relações de cooperação nos impossibilita realizar um exercício do tipo "estado da arte", resta então o desafio de descobrir "o melhor caminho das pedras". Ou melhor, como proceder para mapear adequadamente um certo panorama de idéias produzido sobre um tema de interesse incontestável para cientistas sociais e políticos? Tema que, por seu turno e sob um ângulo específico, vem ganhando cada vez mais visibilidade dentro de distintos campos discursivos, como o governamental, o não-governamental e o político-partidário. É quando

\footnotetext{
${ }^{1}$ Um campo de estudos deve ser entendido como um conjunto de formulações que nasce e toma vigor pelo reconhecimento de que um determinado tema, ou conceito torna-se instaurador de uma problemática e objeto de diálogos, discussões e pesquisas freqüentemente interdisciplinares. Os conceitos de "parentesco", "família", "campesinato", "gênero" podem ser utilizados como exemplo. Com base nas análises de Bourdieu sobre o "campo intelectual", Heilborn (1992) acentua que a análise de um campo de estudos deve-se ater a certos procedimentos metodológicos de verificação dos agentes de produção ali presentes, de listagem de obras, de temas e bibliografias convergentes.

2 É importante ressaltar a visibilidade que a temática da cooperação adquiriu na área das Relações Internacionais, a partir do desafio intelectual que se impôs a esse campo de conhecimento de desvendar as particularidades das relações internacionais contemporâneas. A ampliação dos mercados, o impacto dos processos de integração regional, a economia política da globalização e a internacionalização das sociedades exigiram, portanto, a renovação do conhecimento e novos esforços analíticos para o entendimento dos grandes fenômenos da vida internacional. No que se refere à experiência da cooperaçâo, sua abordagem pode ser encontrada na literatura produzida sobre processos de integração regionais, como o Mercosul. "Cooperação, Integração e Processo Negociador: a construção do Mercosul", de Alcides Costa Vaz, é um bom exemplo de um estudo que busca analisar as novas dimensões - a cooperação e a negociação internacional - que hoje se revelam para o conhecimento das Relações Internacionais.
} 
a noção de cooperação é articulada à noção de integração regional, à idéia de promoção de desenvolvimento econômico-social e de desenvolvimento sustentável, por exemplo.

A reflexão que segue parece-nos oportuna, na medida em que, cada vez mais, hoje, no mundo, a construção de parcerias e de rede de cooperadores para a implementação de uma pluralidade de ações - seja no contexto de programas de desenvolvimento ou de ações de cidadania - vem se tornando, senão uma condição, um dos instrumentos mais procurados para a viabilização de projetos voltados à ajuda de um vasto espectro de beneficiários. Assim, populações tradicionais, comunidades, grupos étnicos e universos maiores encerrados na totalidade de um país, através de suas representações governamentais e nãogovernamentais, são e podem ser considerados alvos da cooperação. Esta será empreendida por agentes ou agências diversas criadas e especializadas para viabilizar mecanismos cooperativos ou formas de apoio abrangendo recursos humanos, técnicos e/ou financeiros. ${ }^{3}$

A partir desse quadro, pode-se indagar até que ponto esse ideal de cooperação não estaria refletindo - e conservando - os pilares de uma tradição de pensamento orientada pela idéia de uma razão universal modeladora da ordem e capaz de instaurar ordens sociais ideais racionalmente planejadas em contextos percebidos como desordens. Ou se, no âmbito dos discursos que julgam os processos cooperativos como inexoráveis em nossa contemporaneidade, levam-se em conta as especificidades e dinâmicas locais, as indeterminações e a imprevisibilidade que marcam as interações sociais, bem como os campos de poder e de disputas em que elas ocorrem.

Essas questões parecem-nos importantes a fim de que não se criem ilusões em relação à neutralidade de certos processos. É bom lembrar que o apoio e a concessão de recursos e empréstimos para implementação de políticas, programas e projetos - seja qual for o seu foco e independentemente de sua importância para os beneficiários - ocorrem dentro de um campo de interesses não movimentado apenas pela benevolência gratuita. Tomando de empréstimo as palavras de Bourdieu, "não há desinteresse que não expresse um sistema de interesses específicos", daí existir na cooperação, como argumenta Douglas,

\footnotetext{
${ }^{3}$ Convém ressaltar que, se após a Segunda Grande Guerra, os arranjos políticos e alianças internacionais foram orientadas pela questão da segurança, no eixo Leste-Oeste, e pela questão do desenvolvimento econômico-social, no eixo Norte-Sul, hoje, intensificou-se o debate acerca de temas antes irrelevantes, assim como passou-se a observar a influência de novos (ONG's) e antigos (igrejas, empresariado) atores na definição de temas prioritários ( meio ambiente, direitos humanos e das minorias, combate ao narcotráfico e ao terrorismo, etc.) para a agenda internacional.
} 
confiança e solidariedade, assim como desconfiança e suspeita tão profundas que podem ser capazes de frustrar suas melhores intenções e propósitos.

Esse artigo não tem a pretensão de ser exaustivo e completo, tal como uma revisão crítica das abordagens elaboradas sobre processos e relações cooperativas nas diversas dimensões em que elas possam ocorrer. Sua intenção é a de realizar uma incursão na tradição do pensamento sociológico e antropológico de modo a sinalizar referenciais teóricos que possibilitem entender melhor as representações que hoje se agregam à prática da cooperação.

\section{Mapeando limites: cooperação e outros conceitos}

Dentro da tradição sociológica, pode-se afirmar que a cooperação estabelecida entre indivíduos, grupos e categorias sociais constitui uma das formas de ação coletiva que mais despertaram interesse de estudo, na medida em que a própria sociedade é entendida como "uma extensa rede de colaboração entre os mais diversos atores sociais" (Howard Becker, 1977). Assim, embora se admita que o conflito e a competição sejam processos intrínsecos aos sistemas sociais, considera-se a cooperação uma relação primordial, visto que, sem ela, não pode existir sociedade.

No verbete do Dicionário de Ciências Sociais, o termo cooperação se define como "qualquer forma de trabalho em conjunto, em contraste com concorrência ou oposição. Em economia e história social o termo é empregado (como o adjetivo cooperativo) para descrever qualquer forma de organização social ou econômica que tem por base o trabalho harmônico em conjunto, em oposição à concorrência". 4

Como forma de ação coletiva imprescindível à integração da sociedade, a cooperação vem sendo analisada sob ângulos diversos. Processos cooperativos são estudados a partir do pressuposto da interdependência que se instaura nos mais diversos níveis de interação social, da complementaridade de interesses que aproxima grupos e categorias profissionais, bem como do dissenso e antagonismo produzidos nesses mesmos processos. No último caso, instaura-se a cooperação antagônica, ou o que Sumner define

\footnotetext{
${ }^{4}$ Dicionário de Ciências Sociais. 2.ed. Rio de Janeiro: FGV/MEC, 1987.
} 
como um "grande esforço racional no sentido de superar antagonismos menores a fim de se trabalhar em conjunto por interesses maiores". 5

Segundo Lewis Coser (1987), a definição de Sumner parece ter-se inspirado nas formulações da economia clássica, sobretudo em Adam Smith, para quem a divisão do trabalho representa a expressão da constante necessidade humana da cooperação e assistência de seus semelhantes na busca da satisfação de interesses próprios. Escreveu Smith: "O homem tem oportunidades quase constantes de receber ajuda de seus irmãos e é inútil esperar essa ajuda apenas como benevolência... não é a benevolência do açougueiro, do cervejeiro ou do padeiro que nos proporciona nosso jantar, e sim a preocupação de cada um deles com seus próprios interesses". 6 Esboça-se aqui e na definição de Sumner a sinalização de que os processos e relações cooperativas, por primordiais que sejam, admitem o conflito de interesses. Contudo, nessas abordagens, "não se investe no conflito", isto é, não há valorização dos antagonismos e disputas como fatores de desagregação dos sistemas sociais, ou como relações que podem inviabilizar processos cooperativos.

Embora a Sociologia tenha surgido a partir da necessidade de se realizar uma reflexão sobre as crises e antagonismos experimentados pela nascente sociedade industrial, a análise da tradição sociológica revela-nos que a unidade do individuo e a unidade formada pelos indivíduos: a sociedade, bem como a problemática da ordem, do equilíbrio e da continuidade dos sistemas sociais - garantidas pelas relações cooperativas constituíram o grande eixo sobre o qual a Sociologia se ergueu. Assim, a grande questão formulada pelos cientistas sociais do século XIX era: o que manteria unida a sociedade quando esta se tornasse maior, mais heterogênea, complexa e diferenciada?

Para Spencer a resposta encontrava-se relacionada diretamente à interdependência crescente e à necessidade da cooperação a ser estabelecida entre componentes especializados (Turner, 1999). Seguindo uma perspectiva semelhante, Durkheim argumentava que a expansão da divisão do trabalho deflagrada com a revolução industrial representava a possibilidade da construção de uma nova forma de solidariedade social que iria garantir uma vida coletiva harmoniosa e integrada, pelo reconhecimento da interdependência instaurada no processo produtivo e de trabalho (1990). As relações

\footnotetext{
${ }^{5}$ Idem, p. 272.

${ }^{6}$ Smith, Adam. The Wealth of Natios. The Modern Library Edition. New York, Random House, 1937, p.14. Citado in: Dicionário de Ciências Sociais. 2.ed. Rio de Janeiro: FGV/MEC, 1987, p. 272.
} 
cooperativas seriam garantidas não pela submissão dos agentes sociais a um conjunto de crenças e ideais compartilhados e coincidentes.

Com a divisão do trabalho, aumentariam o rendimento das forças e laços sociais, a cooperação e a solidariedade, em decorrência da individualização das funções e da interdependência criada pelo reconhecimento das diferenças individuais. A sociedade se tornaria, então, mais capaz de se mover em conjunto. Por analogia ao que se observa em relação ao funcionamento orgânico dos animais superiores, onde a unidade do organismo é tanto maior quanto mais acentuada for a individualização das partes, Durkheim sustenta que, com a divisão do trabalho e com a especialização da produção, cresceria a interdependência entre os indivíduos ou grupos, nascendo entre eles uma solidariedade de tipo orgânica e relações positivas ou de cooperação (1990:84).

Sem enveredar aqui por uma crítica a uma vertente teórica que não encontra respaldo na forma como percebemos a vida organizada de que somos parte, vale acentuar, entretanto, o que ela possui de estimulante: para além da primazia do consenso social e da óbvia idealização da sociedade e da sociabilidade, essa perspectiva pronuncia-se contra a ideologia individualista-economicista que à época presidia a afirmação do mercado como princípio organizador da vida social. Durkheim, ao contrário, embora não negue a dimensão egoísta e utilitária do indivíduo, afirma que ela pode ser considerada como produto de uma sociedade que, tendo atingido um elevado nível de complexidade e diversificação, propiciou a exacerbação das diferenças e do individualismo. Ainda assim, segundo ele, “... arrastado pela coletividade, o indivíduo desinteressa-se de si mesmo e dáse por inteiro aos objetivos comuns..." (1990: 58)

Em relação à perspectiva marxista, tendo a análise se desviado da primazia do consenso social para a lógica que preside o funcionamento das relações capitalistas de produção e para as contradições e desigualdades sociais constituídas nesse contexto, para além de seu legado histórico e político, ressalta-se o fato de ter inspirado uma linha de estudo conhecida como "teoria do conflito" ou "sociologia do conflito".

Do ponto de vista de Marx, todas as estruturas da organização social revelam desigualdades e, no capitalismo, a organização coletiva da produção (nas fábricas) encontra-se em contradição quanto à propriedade privada de bens e à obtenção de lucro por poucos a partir do trabalho cooperativo de muitos. (Ianni, 1988). Desse modo, não há como 
surgir, como imaginava Durkheim, uma forma de solidariedade organicamente instaurada pelo reconhecimento - por parte dos agentes da produção gerada sob a divisão do trabalho - de que todos, na sociedade industrial, dependem uns dos outros.

Todavia, se há em Durkheim a idealização de um tipo de sociedade organizada segundo a lógica da interdependência e da cooperação instauradas no processo de trabalho, Marx, por seu turno, ao propor a superação das condições capitalistas de produção - e da dominação de uma classe sobre outra - pelas condições socialistas e comunistas, termina definindo um modelo não menos idealista. A nova ordem advinda da superação do capitalismo consolidaria uma sociedade justa, marcada pela harmonia de interesses, isenta de conflitos de classe e verdadeiramente cooperativa .

Que horizontes nos propõe, por sua vez, a sociologia de inspiração weberiana para pensarmos a cooperação social? Antes de tudo, a análise das interações - cooperativas e conflitantes - em Weber, decorre de sua própria abordagem das relações sociais. Estas não estão condicionadas por um modo de produção, mas derivam, nascem e se reproduzem na interação dos múltiplos sentidos segundo os quais os indivíduos orientam, reciprocamente, suas ações e condutas uns com os outros.

Weber concebe a relação social como a probabilidade de seus participantes orientarem-se num sentido determinado, configurando, assim, uma ordem que exige legitimação por parte dos que partilham de seu conteúdo. Contudo, os homens não mantêm entre si apenas relações de amizade, de confiança e de concórdia, mas igualmente entram em oposição uns com os outros experimentando conflitos e antagonismos diversos que podem desencadear desde a luta belicosa à concorrência erótica ou à emulação. Para Weber, conflitos e antagonismos são inerentes à experiência humana, já que, no mundo, a multiplicidade de valores e fins gera confrontos sustentados por uma irracionalidade diante da qual a própria racionalidade sucumbe (Freund, 1987).

Ainda que a cooperação seja priorizada dentro de tradições que, antes de tudo, preocuparam-se com a ordem e o equilíbrio dos sistemas sociais, as abordagens marxista e weberiana abriram caminho para análises que partem daquilo que parece contrariar a própria idéia de cooperação, a saber, as trocas insatisfatórias e desiguais que se estabelecem entre as partes envolvidas numa relação cooperativa. Ou ainda, as situações em que as trocas e poder de barganha encontram-se assimetricamente constituídos, fazendo com que a 
cooperação resulte em drásticas rupturas ou em relações de dominação, sejam quais forem as nuances e ambigüidades presentes nesses processos.

Simmel parece sugerir um caminho inverso ao proposto por aqueles que vêem o conflito/desordem como fenômenos negativos, ou a partir dos fatores de dissociação que dele resultam ou que o acompanham. Para o autor, cabe perguntar, antes de mais nada, se o conflito não é, enquanto forma de interação humana, uma forma de sociação, ou de se alcançar algum tipo de unidade, e não simplesmente de dissociação, já que associado à aniquilação de uma das partes conflitantes : "O conflito é um fato sui generis e sua inclusão sob o conceito de unidade teria sido tão arbitrária quanto inútil, uma vez que o conflito significa negação da unidade"(Simmel, 1993:123).

Não existem, entretanto, grupos absolutamente centrípetos e harmoniosos, já que o social, para alcançar uma configuração qualquer, precisa tanto da harmonia quanto da desarmonia, da associação e da competição. Daí se depreende que a unidade pode ser designada como consenso, mas também como síntese de energias onde estão incluídas discordâncias e oposições. A proposta de Simmel parece-nos adequada por buscar uma interpretação dialética das situações de conflito, ou procurar, nas interações sociais entre indivíduos ou grupos, processos que, embora lidos como desagregadores ou aniquiladores de uma das partes envolvidas, por vezes carregam, na oposição, algum tipo de consenso ou unidade. Assim, resulta que o antagonismo entre os agentes sociais pode sugerir a existência de relações cuja unidade reside na tensão e não na harmonia.

$\mathrm{Na}$ teoria antropológica, o deslocamento do foco das relações de equilíbrio e das representações de consenso para as relações de conflito e representações de dissenso se inicia a partir do momento em que a antropologia política se estabelece como um campo específico de estudos. Ressaltam-se as situações neo-colonialistas de contato entre europeus e africanos como instauradoras de novas preocupações para a antropologia ${ }^{7}$. A partir daí, as relações sociais vão ser vistas também como relações de dominação, as quais vão coexistir com a resistência e em contextos em que as culturas vão atuar na definição, transformação e reprodução dessas relações de força.

7 Balandier (1969) destaca, sobretudo, o fato de ter sido a África o grande terreno de onde avançaram as pesquisas sobre o conteúdo político e conflitante das relações sociais. 
Dentre os trabalhos realizados sob essa inspiração, destaca-se a coletânea "African Political Systems", publicado em 1940 por Fortes \& Evans-Pritchard. No que se refere à análise da cooperação no contexto das situações de contato, o estudo realizado por Gluckman para essa coletânea enriquece e amplia o olhar sobre as relações cooperativas: o autor investe na investigação sobre a oposição surgida entre grupos semelhantes e as lealdades conflitantes em relação às diferentes autoridades constituídas, no contexto da colonização da Zululândia. Se antes a nação era uma organização estável, onde a oposição se dava nas relações entre tribos por sua vez unidas através da figura do rei, no contexto da moderna administração política da Zululândia, dois grupos de cor representados por distintas autoridades passaram a traduzir uma outra forma de oposição, desta vez dominada pela força superior do Governo.

Segundo Gluckman (apud Kupper,1978), embora existisse uma oposição simbólica e concreta entre zulus e europeus, eles eram forçados a interagir em esferas de interesse comum, associando-se em celebrações e atuando por costumes de cooperação e comunicação. Essas situações, embora marcadas pela existência de vínculos provisórios, também explicitavam tensões representativas de um sistema social onde os conflitos só se resolveriam por meio de mudanças estruturais radicais. Todavia, a permanência dos vínculos e a ocorrência dos conflitos no contexto dos processos cooperativos na Zululândia, veio demonstrar a possibilidade da coexistência da aliança e da oposição entre indivíduos e grupos, bem como os paradoxos e ambigüidades que se instauram no contexto das relações sociais, onde se incluem as relações de cooperação.

$\mathrm{Na}$ tentativa de realizar um balanço das perspectivas de análise surgidas no campo da antropologia política, a partir da investigação das situações de contato entre sociedades européias e sociedades tribais e, conseqüentemente, entre colonizadores e colonizados, em "Antropologia e Poder", Caldeira afirma que:

"A mudança na maneira de se conceber o foco da antropologia política vem sendo acompanhada por várias outras mudanças que a complementam. Uma segunda mudança clara foi do estudo de sociedades e povos tribais (ou do estudo de sociedades sem estado ou de estados primitivos) para o estudo da constituição do mundo moderno. Três temas são importantes aqui: o encontro colonial; as interconexões de grupos e culturas; e o estudo de sociedades e culturas contemporâneas no chamado terceiro mundo... Nesse sentido, uma Antropologia dos encontros coloniais tende a explorar não só as relações de 
dominação e desigualdade entre os colonizadores ocidentais e os povos colonizados do terceiro mundo, mas a produção de situações e culturas específicas como resultados desses encontros"(1989:5)

Daí se depreende o pressuposto de que a existência de uma ordem capitalista internacional não resultou numa forma padrão de relacionamento entre as nações conectadas. Ou seja, esta ordem conectou de maneira desigual as nações do mundo, e o entendimento das interdependências e relações cooperativas - em geral assimétricas geradas nessa conexão deve levar em conta as especificidades locais, o contexto histórico em que o encontro foi produzido, bem como as ênfases sublinhadas em torno do encontro, dentro do campo discursivo criado a partir dele.

Um conjunto de reflexões extremamente fecundas vem consolidando, a partir dessa nova era de integração planetária e das preocupações e impasses daí decorrentes, sobretudo no campo da antropologia, uma área de estudos voltada para a compreensão dos processos e programas de cooperação para o desenvolvimento, ou para o impacto que esses processos vem causando junto às populações beneficiárias dessa modalidade de intervenção e apoio.

No contexto das análises e literatura produzidas sobre o tema, ressalta-se como ponto de partida o próprio questionamento da categoria "desenvolvimento" e das "linguagens" e mecanismos de poder que ela instaura, no domínio discursivo e não discursivo, no âmbito das palavras e das práticas institucionais. Como exemplos dessa produção, podemos citar, dentre tantos esforços, o de Jonathan Crush, com "Power of Development"; Gilbert Rist, com "The History of Development: from western origns to global faith"; Emma Crewe e Elizabeth Harrison, com "Whose Development? An Ethnography of Aid"; Lucy Mair, com "Anthropology and Development"; e Arturo Escobar, com "Encountering Development: the making and the unmaking of the third world", leitura obrigatória para quem se aventura no desafio de compreender as múltiplas alianças estabelecidas nesse processo e dinâmica da integração mundial articulada à noção de desenvolvimento.

Há que lembrar ainda as contribuições de Pierre Bourdieu para o entendimento da cooperação, embora em sua vasta produção teórica não encontremos análises que possam ser reconhecidas como incursões ao campo da sociologia do desenvolvimento e da ajuda. Todavia, suas formulações, particularmente as que resultam de sua teoria dos campos 
sociais, constituem um bom caminho para o entendimento das relações cooperativas e conflitantes entre agentes sociais em micro e macro esferas, na medida em que tratam o universo social funcionando como campos que movimentam diferentes espécies de capital e de lutas. ${ }^{8}$

Para Bourdieu, a sociedade ganha visibilidade através de espaços sociais que se particularizam pela manifestação de relações de poder, onde os agentes vão lutar em torno de interesses específicos, ocupando posições previamente fixadas e determinadas pelo capital social por eles adquirido. Assim, os agentes que desfrutam de posições hierarquicamente reconhecidas como superiores, possuem maior prestígio e o poder de impor, aos demais, aquilo que lhes parece melhor e conveniente. Criam-se entre eles relações de dominação e, tendo os mesmos interiorizado um conjunto de visões e divisões, valores, crenças e representações, por meio de suas ações e discursos, a lógica do funcionamento dos campos tenderá a se reproduzir, como acentua Bourdieu (1987), “de uma maneira relativamente imprevisivel", mas sem atingir os princípios de poder que o estruturam.

Tal perspectiva de análise traz embutida uma advertência: a de que os processos cooperativos sejam analisados a partir do reconhecimento de que quaisquer que sejam as formas de apoio, a concessão de recursos e empréstimos para implementação de políticas, programas e projetos - seja qual for o seu foco e independentemente de sua importância para os beneficiários - estaremos tratando de práticas e relações que ocorrem, como já foi dito anteriormente, dentro de um campo de interesses não movimentado apenas pela benevolência gratuita. A cooperação envolve uma sucessão de encontros entre determinados agentes que propiciam a estruturação de um campo de poder, marcado por confrontos e alinhamentos em torno da orientação de consensos sobre as condições e o

\footnotetext{
${ }^{8}$ A teoria dos campos sociais de Bourdieu tem sido fartamente utilizada em estudos que hoje se dedicam à compreensão do cenário marcado pela politização do meio ambiente, o qual fez surgir novos atores sociais e políticos no contexto da globalização. Discute-se a conformação de um campo de poder e de lutas, isto é: “de um campo polinucleado de poder, onde os principais agentes traduzem-se em núcleos que atuam como matrizes geradoras e difusoras de ideários; lógicas, modelos de intervenção; regras e normas que orientam a criação de novos direitos e deveres; sistemáticas de financiamento; princípios e recomendações básicas para a formulação de políticas ambientais globais, nacionais e locais." (Barros, 1996:127).
} 
próprio significado daquilo que se pretende alcançar, seja o "desenvolvimento sustentável”, a "inclusão social", o "exercício da cidadania", etc. E mesmo quando seja admitida a incorporação das formulações que advenham, eventualmente, de movimentos sociais locais ou nacionais, essas proposições só se tornam influentes no cenário global quando circulam nos circuitos de poder mundial onde o peso dos agentes-núcleos é fundamental.

Esse breve mapeamento de idéias e reflexões geradas em torno do conceito de cooperação - ou das discussões que para ele convergem - trouxe-nos, antes de tudo, a grande contribuição da advertência. A primeira refere-se ao fato de que a sublinhada polissemia que envolve o conceito - além da multiplicidade e da dinâmica inesgotável de experiências agrupadas sob essa rubrica - reflete sua imprecisão e instabilidade como instrumento analítico. O recorte do universo a ser investigado e a definição de um referencial teórico - como, por exemplo, a teoria dos campos - que nos ajude a pensar como determinadas relações sociais se estabelecem em contextos específicos tornam-se fundamentais.

Por outro lado, estamos certos de que, para além das dificuldades de se pensar um "conceito que não escapa à polissemia" (Guimarães, 2000), está a dificuldade de analisar processos sociais de ampla magnitude e de temporalidade irrestrita, na medida em que estes se encontram condicionados por fatores reais e ideais, pela volição e liberdade humanas, bem como pelo acaso (Jaguaribe, 1999). Assim, os limites da análise das práticas cooperativas serão dados pelo próprio entendimento de que, em relação ao objeto em questão, pode-se tentar mapear certos aspectos e fatores que imprimem às relações sociais sentidos específicos. Contudo, o reconhecimento de que a liberdade humana produz significados inesperados e a certeza de que o mundo é também puro acaso colocam-nos, antes de tudo, diante da imprevisibilidade das formas pelas quais vão atuar agentes sociais e históricos dentro de circunstâncias concretas, gerais e também difusas.

Em seguida, segue-se a constatação de que, uma vez estabelecido o recorte, a literatura vinculada ao tema reflete o comprometimento de um grande número de pesquisadores com a legitimação de certos atores - representados como "novos" - e a validação de certos modelos de ação - em parceria e em "rede de cooperadores" - para execução de políticas e programas governamentais e não-governamentais os mais diversos. 
Nesse sentido, apesar dos méritos desses trabalhos, parece que o esforço dirigido à defesa de certos modelos e ideais reduz a possibilidade do distanciamento, ou de um olhar crítico em relação à realidade investigada. Assim, para que o ativismo político não se sobreponha ao questionamento e à crítica, torna-se necessário aprofundar discussões e investir na pesquisa. Somente por esse caminho, talvez seja possível reunir elementos que nos permitam pensar a cooperação não somente sob ângulo do encantamento que reveste suas atuais representações, mas a partir de uma base sólida de conhecimentos que possa, quem sabe, produzir uma linha específica de estudos: a "sociologia da cooperação" ...

\section{Considerações Finais}

Com o desenvolvimento da ordem capitalista internacional, nações $e$ intenções foram conectadas, mobilizando os mais diversos atores e objetos de luta, ou objetos pelos quais se passou a defender e a lutar. A cooperação internacional para o desenvolvimento pode ser vista como fruto desse processo. Processo que suscitou objetividades discursivas novas e paradigmáticas, amparadas cientificamente e professadas por todos aqueles a quem foi concedido o direito de falar, de propor a mudança e de intervir, com o respaldo dessa legitimidade, em universos imersos em "desordens" totalmente contrárias ao novo padrão civilizatório procurado.

Como acentua Guimarães (op.cit), nas relações de dominação, os detentores de poder sempre vislumbram um horizonte temporal dilatado e sempre se persuadem - e buscam persuadir aos dominados - que seu poder é legítimo... A conhecida elaboração weberiana da dominação pode ser verificada nas relações internacionais: a supremacia justifica-se pela forma carismática, pela tradição e, cada vez mais, pela racionalidade instrumental moderna.

Em suas análises sobre o desenvolvimento - e o subdesenvolvimento - enquanto discursos historicamente produzidos, Escobar comenta que "...in the history of the modern West, non European areas have been systematically organized into, and transformed according to, european constructs. Representations of Asia, Africa, and Latin America as Third World and underdeveloped are the heirs of an illustrious genealogy of western conceptions about those parts of the world" (1995:7). Assim, caberia examinar por que 
razões, a partir de um determinado momento, alguns países começaram a se ver como subdesenvolvidos e por que o desenvolver-se tornou-se para eles um problema fundamental, assim como passou a ser legítima a proposta da intervenção externa como $\underline{\text { meio de se viabilizar o desenvolvimento perseguido. (grifo meu) }}$

Um aspecto importante a ressaltar é que, tanto no espaço multidimensional das relações entre doadores e receptores de modernidade, quanto nos diversos subcampos que o compõem, embora os ocupantes das posições dominantes e dominadas estejam envolvidos em lutas de diferentes formas, não necessariamente se representam como antagonistas: em certos momentos e relações, apresentam-se como parceiros, estabelecendo trocas de diversas naturezas, cooperando por objetivos comuns, construindo solidariedades e interdependências. Algo similar às situações analisadas por Gluckman, no que diz respeito às interações cooperativas temporárias e provisórias estabelecidas entre os zulus e os europeus.

Segundo Bourdieu, esse tipo de concordância resulta do fato de que, "As categorias de percepção do mundo social são essencialmente produto da incorporação das estruturas objetivas do espaço social. Em conseqüência, levam os agentes a tomarem o mundo social tal como ele é, a aceitarem-no como natural, mais do que a rebelarem-se contra ele" (1989:141). Nesse sentido, instauram-se conflitos, mas também alianças e ambigüidades entre dominantes e dominados. Simultaneamente, surgem mediadores dessa relação e anuncia-se o que se pode ou não se permitir a si mesmo, o que implica uma aceitação tácita das posições ocupadas no campo e um sentido de limites para as transformações efetuadas.

Cabe lembrar ainda que se tenta inculcar essa nova modalidade de implementação de políticas e projetos de desenvolvimento não mais a partir da polarização Norte-Sul, mas da sua articulação, o que não significa que na transição do plano retórico-discursivo para o prático-operacional não surjam divergências que dificultem e debilitem as inovações testadas. A começar pelo fato real de que o mundo continua dividido e fragmentado, o que cria ameaças difusas e, conseqüentemente, apelos à formação de alianças - militares, econômicas, políticas e culturais - para combater os males difusos oriundos da periferia do mundo. Nesse sentido, é provável que essa criação de blocos aliados ou cooperativos e solidários tenha um impacto negativo sobre o imaginário do bloco periférico. Tal possibilidade, no entanto, gera a contrapartida da parceria: para que se evitem 
ressentimentos, é providenciada a retórica da inclusão e do envolvimento seletivo - entre os aliados - de candidatos à luta pela consolidação da democracia, da liberdade e em prol das inúmeras bandeiras defendidas no mundo ocidental.

Por outro lado, convém lembrar que essas experiências estruturam-se por meio de uma rede diferenciada de agentes que, embora re-encantados pelos ideais de solidariedade e novos pactos a serem construídos em prol de um bem comum, movimentam-se dentro de um campo de lutas. Conflitos serão, portanto, inevitáveis. Não para provocar uma drástica desagregação das partes, mas no sentido de manter uma tensão, ou uma unidade indicadora de um consenso que, conforme a leitura de Simmel, parece inerente à lógica de funcionamento de um campo que pressupõe hierarquias e polarizações movimentando-se e reatualizando-se dentro de um combinado de acordos governamentais, consensos cordiais, manobras, adaptações e resistências.

Por outro lado, é bom lembrar, como acentua Foucault (1992), que onde há poder há resistência, assim como o caráter relacional do poder implica que não se pode vê-lo como uma relação unívoca e unilateral. O pressuposto teórico de que os agentes disputam dentro de um campo de lutas que os posiciona - em função de um quantum adquirido - em um pólo dominante e outro dominado não significa que se estabeleça entre eles um sistema de dominação e de sujeição absoluto. Apesar de permanecerem inalterados os princípios que estruturam os campos dentro dos quais os agentes se inserem, margens de manobra, manipulações e reciprocidades de diversas ordens podem surgir. Talvez aí resida a complexidade e a dialética - bem como a imprevisibilidade - de um processo que contém e proporciona tanto os elementos da mudança quanto os da reprodução daquilo que se quer transformar.

Segundo Scherer-Warren, “... a solidariedade define-se pelo princípio de responsabilidade individual e coletiva com o social e o bem comum, cujas implicações práticas são a busca da cooperação e da complementaridade na ação coletiva e, portanto, para o trabalho em parceria... As parcerias caracterizam-se pela relevância que atribuem à complementaridade de esforços, pelos princípios de cooperação e solidariedade na realização de um programa social" (op. cit., 62)

É provável que, em se tratando da cooperação, estejamos diante de uma tendência ou de processo inexorável a ser compartilhado no mundo. Contudo, estamos também diante 
de ideais e de utopias de construção de sociedades mais democráticas, abertas ao pluralismo e à articulação de forças sociais múltiplas e diversas. Se hoje o mundo tenta atuar "em rede", ou pela complementaridade de esforços para realização de metas e projetos comuns, confrontos, compromissos, alianças e descaminhos são parte intrínseca desse processo pelas diversas razões anteriormente discutidas. Portanto, antes de tudo, devemos providenciar o seu desencantamento, ou a retirada de sua maquiagem, se temos a intenção de compreendêlo em suas ambigüidades, contradições, impasses, ambições veladas e explícitas.

Trata-se, como propõe Casanova, de admitir que, se a cooperação é também uma forma de ampliação das lutas contemporâneas, deve-se incluir o conflito como parte essencial das experiências cooperativas, ao invés de supor, como é muito freqüente, que “quando há cooperação não deve haver conflito entre os que cooperam" (2002:265, 267). Assim, segundo o autor, devemos introduzir racionalmente o conflito na formulação da investigação, eliminando o desejo de amenizá-lo em nome dos ideais pelos quais lutamos e das posições ideológicas que adotamos.

Portanto, a afirmação de Viola de que "Aqueles que no mundo pré-global estavam separados por conflitos encontram-se hoje, no mundo global, atravessados por idênticas orientações culturais e interesses, estabelecendo parcerias que são o eixo de uma nova governabilidade" (1998:51), ainda parece-nos precipitada. É bom lembrar que habitus, como disposições adquiridas, não se dissolvem tão facilmente no ar, assim com é possível que persistam na ruptura, imprimindo conteúdos específicos às práticas e relações estabelecidas como novas. Assim, a perspectiva de uma futura sociedade planetária estandartizada, que seja ao mesmo tempo diversa e semelhante ou pluralmente constituída por pessoas-planeta, reconhecidas como iguais em direitos e deveres, parece afastada da realidade. Ao que tudo indica, teremos, no máximo, amálgamas locais de formas antigas e novas, já que cada encontro propiciado pelo estreitamento das fronteiras mundiais tem uma lógica própria, dada pelas singularidades de cada contexto.

Por outro lado, embora seja útil e confortável pensar em modelos mais justos e solidários de se organizarem as relações entre homens, mulheres, sociedades e nações, a virtude e o vício parecem estar sempre convivendo. Nas boas intenções da política internacional, nas reciprocidades instauradas entre doadores e receptores de modernidade, 
nas propostas apresentadas como novas, nos discursos da soberania - e nos que lhe são contrários - nos intercâmbios de saber e na cooperação entre tantos parceiros.

Certamente, novos discursos estão sendo produzidos em meio a transformações que destróem modelos praticados no passado pela demonstração de sua incompatibilidade com os novos contextos que se apresentam, dando lugar, assim, à elaboração de contradições. Nesse sentido, é provável que estejamos aqui contrastando regimes de discurso $e$ representação, como propõe Escobar em sua análise do desenvolvimento enquanto experiência histórica produzida tanto no domínio do pensamento quanto no da ação. Diz ele, "Regimes of representation can be analysed as places of encounter where identities are constructed... as places of encounter of languages of the past and languages of the present (such as the languages of 'civilization' and 'barbarism' in postindependence latin America), internal and and external languages, and languages of self and other..."(1995:10).

Resta saber por que, entre os "receptores", sempre vigoram discursos e representações que os posicionam em lugares que se caracterizam a partir da ausência de algo: do desenvolvimento, da competência, do profissionalismo e do savoir-faire para, a partir daí, se construir a demanda da intervenção e, assim, se alimentar a idéia de que somente por esse meio será possível desconstruir suas desordens para que ingressem definitivamente numa nova ordem. O curioso - e lamentável - é que, apesar de todo empenho e cooperação, beneficiários freqüentemente terminam reassumindo sua posição de receptores: dificilmente suprem suas deficiências, não raro se vêem diante de projetos com os quais não podem arcar sozinhos e, assim, voltam a ocupar o lugar que lhes foi reservado no mundo, com sua conivência, cumplicidade e permissão.

\section{Bibliografia}

BALANDIER, Georges.1969. Antropologia Política.SP:Difusão Européia do Livro.

BARROS, Flávia Lessa. 1996. Ambientalismo, globalização e novos atores sociais. In: Globalização e Fragmentação / Revista Sociedade e Estado. Volume XI. n¹. Brasília: UnB. Dept ${ }^{\circ}$ de Sociologia.

BECKER, Howard. 1977. Uma Teoria da Ação Coletiva. Rio de Janeiro: Zahar. BOURDIEU, Pierre. 1989. O Poder simbólico. Rio de Janeiro: Bertrand Brasil. 
CALDEIRA, Tereza P.R. 1989. Antropologia e Poder: uma resenha de etnografias americanas recentes. In: BIB / Boletim Informativo e Bibliográfico de Ciências Sociais. n 27. Rio de Janeiro: ANPOCS.

CASANOVA, Pablo González. 2002. Exploração, colonialismo e luta pela democracia na América Latina. Petrópolis: Vozes.

COSER, Lewis. 1987. "Cooperação" (verbete). Dicionário de Ciências Sociais. Rio de Janeiro: FGV.

CREWE, Emma e HARRISON, Elizabeth. 1999. Whose Development? An Ethnography of Aid. London: Zed Books.

CRUSH, Jonathan. 2000. Power of Development. London \& New York: Routledge.

DOUGLAS, Mary. 1998. Como as instituições pensam. São Paulo: Edusp.

ELIAS, Norbert.199O. A sociedade dos Individuos. Rio de Janeiro: Zahar.

ESCOBAR, Arturo.1995. Encountering Development. The Making and the Unmaking of the Third World. New Jersey: Princeton University Press.

FOUCAULT, Michel.1992. Microfísica do Poder. Rio de Janeiro: Graal.

FREUND, Julien. 1987. Sociologia de Max Weber. Rio de Janeiro: Forense.

GUIMARÃES, César. 2000. Envolvimento e Ampliação: a Política Externa dos Estados Unidos. In: GUIMARÃES, Samuel (org) Estados Unidos: Visões Brasileiras. Brasília: IPRI / Fundação Alexandre de Gusmão.

HELBORN, Maria Luísa. 1992. Fazendo Gênero: a Antropologia da Mulher no Brasil. In: COSTA, Albertina \& BRUSCHINI, Cristina (orgs). Uma Questão de Gênero. São Paulo: Rosa dos Tempos / Fundação Carlos Chagas.

IANNI, Octavio.1988. Marx. Sociologia. São Paulo: Ática.

JAGUARIBE, Hélio. 2000. Mercosul e as Alternativas para a Ordem Mundial. In: GUIMARÃES, Samuel (org.) Alca e Mercosul: riscos e oportunidades para o Brasil. Brasília: IPRI/FUNAG.

KUPPER, Adam.1978. Antropólogos e Antropologia. Rio de Janeiro: Francisco Alves.

MAIR, Lucy. S/d. Antrhpology and Development. London: Macmillan Press.

ORTIZ, Renato(org.)1983.Pierre Bourdieu. Sociologia. São Paulo: Ed.Ática.

PARESCHI, Ana Carolina C. 1997. Realismo e Utopia: O trabalho de Formigas em um mundo de Cigarras. Brasília: Unb. Dissertação de Mestrado.

RIBEIRO, Gustavo L. 1991. Ambientalismo e Desenvolvimento Sustentado. Nova Ideologia / Utopia de Desenvolvimento. In: Revista de Antropologia. No 34. São Paulo: USP.

RIST, Gilbert. 1999. The History of Development: From Western Origins to Global Faith. London\& New York: Zed Books.

RODRIGUEZ, José A. 1990. Durkheim. Sociologia. São Paulo: Ática.

SIMMEL, Georg. 1993. A natureza sociológica do conflito. In: MORAES, E. (org.).

Simmel. São Paulo: Ática.

TURNER, Jonathan. 1999. Sociologia: conceitos e aplicações. São Paulo: Makron.

VIOLA, Eduardo. 1998. Globalização, sustentabilidade e governabilidade no Brasil: avaliação e perspectivas. In: Revista Múltipla. Ano III. n4. Brasília: Linha Gráfica Ed.

WARREN, Ilse S. 1996. Novos atores e práticas políticas ambientalistas na era da globalização. In: Globalização e Fragmentação / Revista Sociedade e Estado. Volume XI. $\mathrm{n}^{\circ} 1$. Brasília:UnB. Dept ${ }^{\circ}$ de Sociologia.

São Paulo: Hucitec.

1999. Cidadania sem Fronteiras: ações coletivas na era da globalização. 